\title{
Displacement Analysis of a Bend Plate Test with Mechanical Loading and Laser Heating
}

by

P. S. Lam

Westinghouse Savannah River Company

Savannah River Site

Aiken, South Carolina 29808

This paper was prepared in connection with work done under the above contract number with the U.S. Department of Energy. By acceptance of this paper, the publisher and/or recipient acknowledges the U.S. Government's right to retain a nonexclusive, royalty-free license in and to any copyright covering this paper, along with the right to reproduce and to authorize others to reproduce all or part of the copyrighted paper. 


\section{DISCLAIMER}

Portions of this document may be illegible electronic image products. Images are produced from the best available original document. 
WSRC-TR-97-00294

\title{
DISPLACEMENT ANALYSIS OF A BEND PLATE TEST WITH MECHANICAL LOADING AND LASER HEATING (U)
}

\author{
P. S. Lam
}

Savannah River Technology Center Strategic Materials Technology Department

Materials Technology Section

Publication Date: September 1997

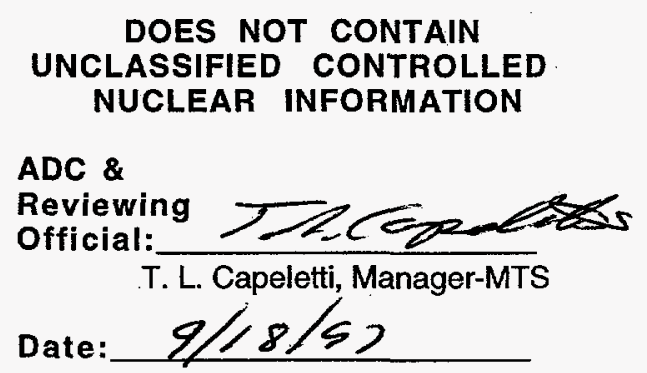

Westinghouse Savannah River Company Savannah River Site Aiken, SC 29808

This document was prepared in connection with work done under Contract No. DE-AC09-96SR18500 with the U. S. Department of Energy 


\section{DISCLAIMER}

This report was prepared as an account of work sponsored by an agency of the United States Government. Neither the United States Government nor any agency thereof, nor any of their employees, makes any warranty, express or implied, or assumes any legal liability or responsibility for the accuracy, completeness, or usefulness of any information, apparatus, product, or process disclosed, or represents that its use would not infringe privately owned rights. Reference herein to any specific commercial product, process, or service by trade name, trademark, manufacturer, or otherwise does not necessarily constitute or imply its endorsement, recommendation, or favoring by the United States Government or any agency thereof. The views and opinions of authors expressed herein do not necessarily state or reflect those of the United States Government or any agency thereof.

This report has been reproduced directly from the best available copy.

Available to DOE and DOE contractors from the Office of Scientific and Technical Information, P.O. Box 62, Oak Ridge, TN 37831; prices available from (615) 576-8401.

Available to the public from the National Technical Information Service, U.S. Department of Commerce, 5285 Port Royal Road, Springfield, VA 22161. 
DOCUMENT: WSRC-TR-97-00294

TITLE: $\quad$ DISPLACEMENT ANALYSIS OF A BEND PLATE TEST WITH MECHANICAL LOADING AND LASER HEATING (U)

\section{APPROVALS}

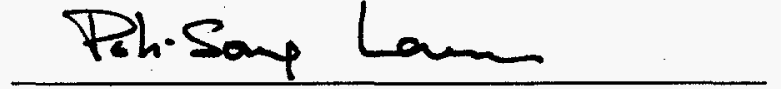

Poh-Sang Lam, Author

Materials Applications \& Corrosion Technology Group MATERIALS TECHNOLOGY SECTION

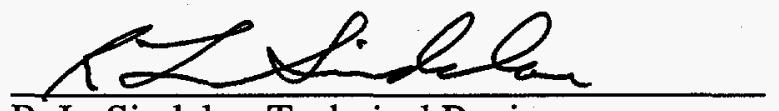

R. L. Sindelar, Technical Reviewer

Materials Applications \& Corrosion Technology Group MATERIALS TECHNOLOGY SECTION
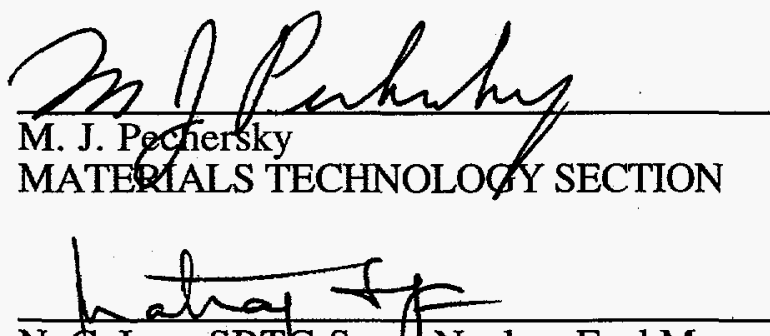

N. C. Iyer, SRTC-Spent Nuclear Fuel Manager Materials Applications \& Corrosion Technology Group MATERIALS TECHNOLOGY SECTION

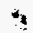

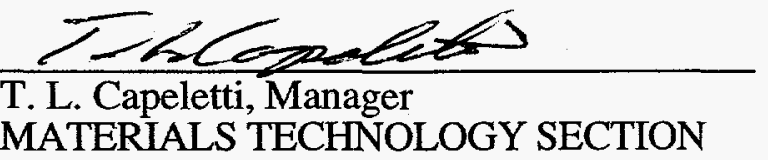

Date:

$9 / 18 / 97$
Date: $9-18-97$

Date: $9-18-97$

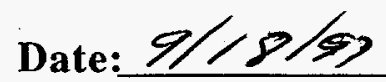


(Blank Page)

$*$

n 


\section{TABLE OF CONTENTS}

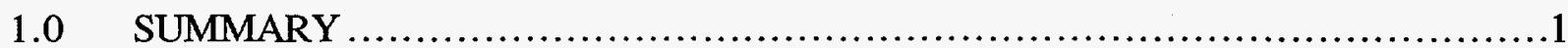

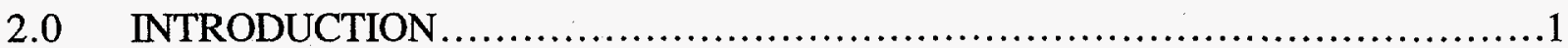

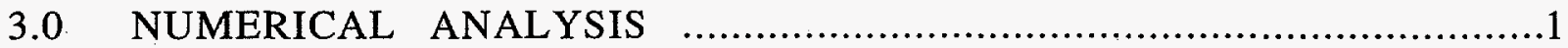

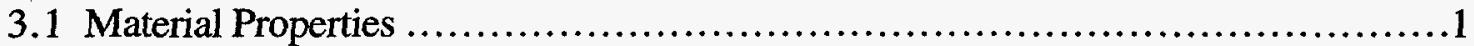

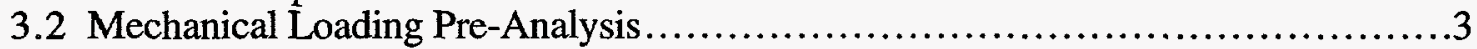

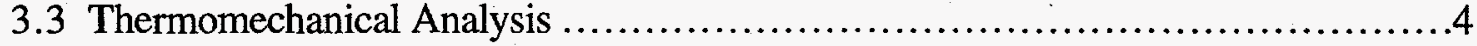

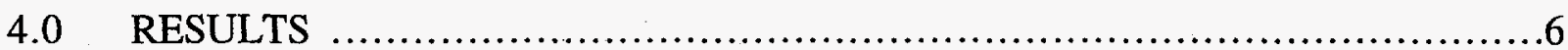

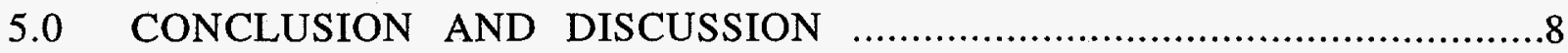

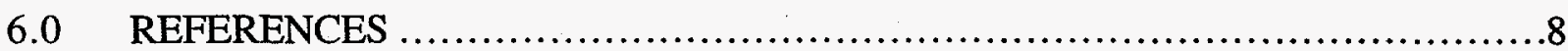

\section{LIST OF TABLES}

Table $1 \quad$ Yield Stresses .................................................................. 2

Table 2 Young's Moduli And Poisson's Ratios …..................................... 2

Table 3 Thermal Expansion Coefficients.................................................... 2

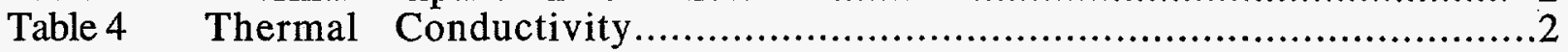

Table $5 \quad$ Specific Heat ...................................................................... 3 
page ii of ii

\section{LIST OF FIGURES}

Figure 1 Finite Element Mesh for the Quarter Plate Model (Pre-Analysis Mechanical Model).

Figure 2 Out-of-Plane Displacements from Plate Center to the Edge along the Long Axis (Comparison of Various Numerical Approaches).

Figure 3 Out-of-Plane Displacements from Plate Center to the Edge along the Long Axis (Comparison of Experimental Data).

Figure 4 Out-of-Plane Displacements from Plate Center to the Edge along the Short Axis (Comparison of Experimental Data).

Figure 5

Figure 6a Typical Temperature Response by Imposing Linear Heat Flux with respect to Time.

Figure $6 b$

Overall Finite Element Mesh for the Half Plate Thermomechanical Model.

Detailed Finite Element Mesh for the Load Cell and Heated Areas of the Half

Plate Thermomechanical Model.

Figure 7 In-Plane Horizontal Displacement Contours after 2046 Newtons (460 lbs) Load Applied to the Plate Center.

Figure 8 In-Plane Horizontal Displacement Contours after the Heated Spot Uniformly Reaches $485 \mathrm{~K}\left(212^{\circ} \mathrm{C}\right)$. Heated Spot is on the Long Axis.

Figure 9 Additional Horizontal Displacement due to Laser Annealing (Figure 8 subtracts Figure 7). Heated Spot is on the Long Axis.

Figure 10

Additional Ver

Figure 11

Relative Displacements in Horizontal Direction with respect to the

Displacement at the Heated Spot. Speckle Fringes were Obtained at the

University of Alabama. Plate Center is on the Left of Heated Spot.

Figure 12 Relative Displacements in Vertical Direction. Speckle Fringes were Obtained at the University of Alabama. Plate Center is on the Left of Heated Spot.

Figure 13 In-Plane Relative Displacements in Horizontal Direction with respect to the Displacement at the Heated Spot. Heat Flux is $494 \mathrm{~W} / \mathrm{cm}^{2}$ and Temperatures $\geq 485 \mathrm{~K}\left(212^{\circ} \mathrm{C}\right)$ at the Heated Spot on the Long Axis.

Figure 14 In-Plane Relative Displacements in Vertical Direction. Heat Flux is 494 $\mathrm{W} / \mathrm{cm}^{2}$ and Temperatures $\geq 485 \mathrm{~K}\left(212^{\circ} \mathrm{C}\right)$ at the Heated Spot on the Long Axis. 


\subsection{SUMMARY}

The surface displacement of a steel plate caused by a permanent deformation as a result of local yielding was modeled by a finite element analysis. The local yielding occurs when a small area of the plate is heated by a laser beam. The calculated displacements are in good agreement with the preliminary experimental data obtained using a bend specimen with laser heating at the University of Alabama at Huntsville. It has been shown computationally and optically that the relative displacements are less than $1 \mu \mathrm{m}$ near the laser heated area of the specimen. The results demonstrate that the experimental approach is a feasible technique for determining the residual stress under multiaxial stress field.

\subsection{INTRODUCTION}

The yield stress of a metal decreases as the temperature rises. This property is used for determining the residual stress with laser annealing $[1,2,3]$. A small area in a structure or a specimen is heated by a laser to relieve the local stresses. Plastic deformation is expected near the heated area due to the lowered yield stress. One complicating factor that must be considered is thermal expansion which reduces the net deformation in a tensile field but amplifies that in a compressive field. Optical speckle interferometry is used to capture this minute surface movement before and after heating. The fringes of the speckle pattern provide the surface displacement measurement. For example, the displacement differential between two fringes is proportional to the wavelength of the laser beam. In the case of Helium Neon laser, the relative displacement between two fringes is $0.4475 \mu \mathrm{m}$.

The experiment involves a 304 stainless steel rectangular plate with an effective dimension of $156 \mathrm{~mm} \times 137 \mathrm{~mm}\left(6.125^{\prime \prime} \times 5.375^{\prime \prime}\right)$. The thickness of the plate is $2.54 \mathrm{~mm}$ $\left(0.1^{\prime \prime}\right)$. A $191 \mathrm{~mm} \times 171 \mathrm{~mm}\left(7.5^{\prime \prime} \times 6.75^{\prime \prime}\right)$ load frame was built so that the plate is simply supported by wires sitting on the grooves near the edges of the load frame. The plate is loaded by tightening a screw at the plate center at a point with a small load cell (Model LBO-500 from Transducer Techniques, Temecula, California). The load cell diameter is 8 $\mathrm{mm}\left(0.3125^{\prime \prime}\right)$ with a lightly curved convex surface (radius of curvature is $51 \mathrm{~mm}$ or $2 "$ ). The pre-loaded plate with the load frame is in a vertical position when the laser heating is applied. The laboratory tests were carried out at the Center for Applied Optics at the University of Alabama at Huntsville (UAH) by Professor Chandra S. Vikram [4].

Numerical finite element analysis provides: 1) Determination of the optimum location in the specimen for applying laser heating, which depends on the achievable stress level due to bending; 2) Determination of the required laser power and the time duration of the heating/cooling cycle. Of course, the calculated displacements can be compared to the optical results to support the credibility of the theoretical and experimental development. The ABAQUS finite element program [5] was used to perform the analyses at the Savannah River Technology Center (SRTC). The finite element meshes were created with the MSC/PATRAN finite element pre/post-processor [6]. The details of the finite element analysis are described in this report.

\subsection{NUMERICAL ANALYSIS}

\subsection{MATERIAL PROPERTIES}

The analysis of laser heating for the 304 stainless steel specimens under uniaxial tension (up to $98 \%$ of the room temperature yield stress) has been previously performed by Miller [7]. The numerical result was in very good agreement with the experimental data. Therefore, the mechanical and thermal properties reported in Reference 7 and in the 
Handbook of Stainless Steels [8] for 304 stainless steel are adopted in the present analyses. The yield stresses in Table 1 were obtained by scaling the temperature dependent yield stresses from Reference 8 with the yield stress at room temperature (318.5 MPa or 46.2 $\mathrm{ksi}$ ) which was provided by the vendor of the plate material [9]. The material properties used in the finite element analysis are summarized in the following Tables.

TABLE 1 Yield Stresses [see above text for reference]

\begin{tabular}{|c|c|}
\hline Temperature $(\mathrm{K})$ & Yield Stress $(\mathrm{MPa})$ \\
\hline 300 & $318.5[9]$ \\
\hline 366 & 264.2 \\
\hline 533 & 207.2 \\
\hline 644 & 188.2 \\
\hline 755 & 171.8 \\
\hline 866 & 156.3 \\
\hline 977 & 139.9 \\
\hline 1089 & 98.4 \\
\hline 1144 & 63.9 \\
\hline
\end{tabular}

TABLE 2 Young's Moduli and Poisson's Ratios [8]

\begin{tabular}{|c|c|c|}
\hline Temperature (K) & Young's Modulus (GPa) & Poisson's Ratio \\
\hline 300 & 195.0 & 0.297 \\
\hline 366 & 192.4 & 0.299 \\
\hline 480 & 183.4 & 0.310 \\
\hline 589 & 176.5 & 0.314 \\
\hline 700 & 166.2 & 0.317 \\
\hline 811 & 155.1 & 0.321 \\
\hline 922 & 145.5 & 0.326 \\
\hline 1033 & 133.8 & 0.332 \\
\hline 1089 & 124.8 & 0.340 \\
\hline
\end{tabular}

TABLE 3 Thermal Expansion Coefficients [8]

\begin{tabular}{|c|c|}
\hline Temperature $(\mathrm{K})$ & Thermal Expansion Coefficient $(\mathrm{m} / \mathrm{m} \bullet \mathrm{K})$ \\
\hline 300 & $17 \times 10^{-6}$ \\
\hline 1200 & $19.6 \times 10^{-6}$ \\
\hline
\end{tabular}

TABLE 4 Thermal Conductivity [8]

\begin{tabular}{|c|c|}
\hline Temperature (K) & Thermal Conductivity $(\mathrm{W} / \mathrm{m} \cdot \mathrm{K})$ \\
\hline 300 & 14.8 \\
\hline 1200 & 29.5 \\
\hline
\end{tabular}


TABLE 5 Specific Heat [8]

\begin{tabular}{|c|c|}
\hline Temperature (K) & Specific Heat $(\mathrm{J} / \mathrm{kg} \cdot \mathrm{K})$ \\
\hline 273 & 395 \\
\hline 760 & 500 \\
\hline 1100 & 545 \\
\hline 1200 & 550 \\
\hline
\end{tabular}

The density values for various grade of the stainless steels range from $8000 \mathrm{~kg} / \mathrm{m}^{3}$ at $-196^{\circ} \mathrm{C}$ to $7400 \mathrm{~kg} / \mathrm{m}^{3}$ at $1000^{\circ} \mathrm{C}$ [10]. A typical value of $7900 \mathrm{~kg} / \mathrm{m}^{3}$ representing an average within the laser heating temperature range is used in the calculations for 304 stainless steel. The film coefficient (also known as the heat transfer coefficient or the convection coefficient) for free convection is set to $5.0 \mathrm{~W} / \mathrm{m}^{2} \cdot \mathrm{K}$ [11] which represents the thermal convection from the specimen surface to the ambient temperature of $300 \mathrm{~K}$. It should be noted that the typical convection coefficient for a horizontal stainless steel plate is about $1.5 \mathrm{~W} / \mathrm{m}^{2} \cdot \mathrm{K}$ [12]. However, in the present case, the plate is placed in a vertical position during the test and the high temperature spot is very small $(2 \mathrm{~mm}$ in diameter on a $156 \mathrm{~mm} \times 137 \mathrm{~mm}$ plate). Under these circumstances, a buoyancy-driven air flow is expected near the heated spot. Therefore, the value of $5.0 \mathrm{~W} / \mathrm{m}^{2} \cdot \mathrm{K}$ is reasonable.

\subsection{MECHANICAL LOADING PRE-ANALYSIS}

This part of analysis was used to confirm the mechanical loading and to determine an optimum location for laser heating in order to produce detectable interferometry fringes as a result of inplane surface movement due to plastic deformation. The ideal location for laser heating is away from the load point to reduce the high stress gradient and to avoid possible interference associated with the load cell, and yet this location should be close to the load point so that the stress remains sufficiently high and yielding can occur by heating. The ABAQUS finite element code [5] was used for analysis. Since this analysis involves only the mechanical load, a quarter model of the plate is sufficient due to symmetry. The top view of the finite element mesh is shown in Figure 1 which contains five layers of solid (three-dimensional) elements through the thickness. There are 2445 elements which include C3D20 (20-noded brick elements) and C3D15 (15 noded triangular prism elements). These are higher order finite elements, therefore, the total number of structural nodes is 11,853 . Note that the radius of the outer-most concentric ring of elements at the lower left corner of the model is $8 \mathrm{~mm}$. The load cell is well contained in this region with a radius of $4 \mathrm{~mm}$.

The point 0 in Figure 1 is the center of the plate. The $\mathrm{X}$-axis and $\mathrm{Y}$-axis are, respectively, the long and short axes of the plate. The load is applied in the positive Zdirection which is perpendicular to the plane of the plate according to the right-hand rule. The plate is simply supported on the four edges. Therefore, the finite element nodes along those edges are constrained in the Z-direction. In Figure 1 the symmetric boundary conditions are applied on the $\mathrm{X}-\mathrm{Z}$ and $\mathrm{Y}-\mathrm{Z}$ planes.

Three finite element analyses were performed: 1) The load cell motion is simulated by a rigid contact surface and the material response is elastic-perfectly-plastic; 2) Traction (or pressure) is applied to the load cell region and the material response is elastic-perfectlyplastic; and 3) Traction is applied to the load cell region and the material response is linear elastic. Note that an elastic-perfectly-plastic material assumes a linear stress-strain relationship with a slope defined by the Young's modulus (Table 2) when the stress is less than the yield stress (Table 1), beyond which the plastic deformation occurs and stress 
remains unchanged (at the level of the yield stress) with the increasing strain until the material fails.

Figure 2 shows that all three calculations gave similar results up to loading at 1112 Newtons (250 lbs). However, it is expected that linear elastic solution is not practical for this problem, and the contact problem is too much more computationally intensive. Therefore, the elastic-perfectly-plastic traction problem was chosen for the thermomechanical calculations in the next phase of the analysis.

The corresponding laboratory testing was performed at UAH. The surface displacements along the long axis and the short axis (both axes pass through the center of the plate) were measured for three load levels ( 278 Newtons or $62.5 \mathrm{lbs}, 556$ Newtons or $125 \mathrm{lbs}$, and 834 Newtons or $187.5 \mathrm{lbs}$ ). The surface displacements were measured by using a Dial Indicator (Model 81-261J, the L. S. Starrett Company, Athol, Massachusetts). Because this plate would be re-used in the laser annealing and speckle interferometry experiment, no permanent deformation was allowed to develop during this confirmatory test. Therefore, the loading for this phase of the experiment was carefully controlled not to exceed 834 Newtons to avoid possible plastic yielding of the plate. The calculated and experimental results are shown in Figures 3 (for long axis) and 4 (for short axis). Note that in Figures 3 and 4 the experimental data points for 1112 Newtons $(250 \mathrm{lbs}$ ) are not a direct result of the test. The values of these data points were obtained by superposing the test data for 278 Newtons (62.5 lbs) and for 834 Newtons $(187.5 \mathrm{lbs})$. The principle of superposition is applicable since the majority of the deformation remains elastic, except, in the immediate vicinity of the location where the plate and load cell are in contact.

The finite element result of this part of analysis has demonstrated that the numerical and the experimental procedures are consistent in the mechanical loading of the plate.

\subsection{THERMOMECHANICAL ANALYSIS}

In the actual test, a mechanical load is first applied to the center of the plate. A biaxial bending stress state is resulted. Laser heating is then applied to the opposite side of the plate where the point load has been applied. It was found in the UAH test that a load of 2046 Newtons (460 lbs) is required and the location of the heated spots (2-mm in diameter) is $5 \mathrm{~mm}$ away from the center of the plate, along either the long or the short axis. This arrangement will render visible and useful optical fringes for measuring the relative displacements of the material points near the heated spot. This surface displacement is due to the permanent deformation as a result of laser heating and the lowered yield stress. If the heated spot is located farther than $5 \mathrm{~mm}$ away from the center, no optical fringes could be obtained under the maximum loading conditions.

This test was simulated by a finite element analysis which includes three sequences :

\section{Step 1 - Mechanical Loading}

At room temperature (300K), the edge-supported plate is loaded to 2046 Newtons (460 lbs) at the center. Biaxial bending stress field (simultaneous bending about the long and the short axes) is formed. The load cell side of the plate is under compression and the laser heating side (opposite to the load cell side) is under tension. The material on both sides of the plate within the load cell diameter is yielded by either tension or compression and the equivalent plastic strain in the center of the load cell region is about $0.8 \%$. In the intended laser heating area ( 2 $\mathrm{mm}$ in diameter and $5 \mathrm{~mm}$ away from the plate center along the long or short axis), the material is slightly yielded with plastic strains about 0.3 to $0.4 \%$. 
Step 2 - Laser Heating and Cooling

The heat flux and heating time for the finite element calculation is chosen based on the use of a 25-Watt rated laser illuminating a 2-mm diameter spot for about five seconds. Assuming the effective power actually delivered to the specimen plate is about one-half of its rating (with another half of the power reflecting away from the metal surface). Therefore, the rate of heat flux rising from zero to a maximum value is set to $80 \mathrm{~W} / \mathrm{cm}^{2} \cdot \mathrm{sec}$ for facilitating the finite element calculation and this value is an approximation for the actual heating process. It is noted that displacements will be caused by material flow when the temperature of the material reaches that of the yield stress. Therefore, as long as the laser power is sufficient to raise the spot temperature up to the melting temperature of the paint, the exact heat flux to the plate is not as important as originally expected.

Two transient thermal analyses are needed to accomplish the heating and cooling cycle. The first calculation is a continuous heating for an extended period of time (longer than the 5-second target time). The result is reviewed for temperature distribution in the heated spot. In the present case, a temperature sensitive paint is applied over the plate at the target laser spot. The paint melts at $485.15 \mathrm{~K}\left(212^{\circ} \mathrm{C}\right)$ and then the spot becomes reflective so that no more heat can be delivered to the plate. Therefore, by examining the calculated temperature profile on the heated spot, one can determine the heating time. The total heat flux is thus 80 $\mathrm{W} / \mathrm{cm}^{2} \bullet \mathrm{sec}$ times the heating time. This information provides a precise heat input for the second set of thermal analysis. Figure 5 is a typical calculated temperature-time response curve corresponding to a heat flux input varying linearly from zero to $358.4 \mathrm{~W} / \mathrm{cm}^{2}$ in 4.48 seconds, and shutting down in 0.005 seconds. The calculated temperature data in Figure 5 were taken from the center of the heated spot. The temperatures at the edge of the heated spot are slightly less than the paint melting temperature. Because the temperature will not be a constant value over the heated spot with a heat flux input in the current finite element model, this temperature profile and heating time were chosen to best represent the temperature sensitive paint melting at $485.15 \mathrm{~K}\left(212^{\circ} \mathrm{C}\right)$.

Alternatively, uniform temperature rise can be imposed directly on the laser heating spot to simulate the effect of temperature sensitive paint (the phase change due to melting is not modeled). In fact, most of the results reported in this report were obtained by raising the temperature uniformly on the heating spot linearly from zero to $485.15 \mathrm{~K}\left(212^{\circ} \mathrm{C}\right)$ in five seconds. It was found that these results do not differ significantly from the result by imposing heat flux. It seems that only the final temperature would affect the local deformation as a result of temperature dependent yielding. The total heat input to the specimen is required to bring up the temperature within a certain period of time. The parametric studies documented in Reference 7 support this conclusion.

After the desired temperature pattern is achieved, the plate is allowed to cool down till a steady state is reached. In the ABAQUS calculations, 1000 seconds is sufficient to cool the plate down to the initial temperature $(300 \mathrm{~K})$. The complete heating to cooling temperature history output from this transient thermal analysis is used as an input to the thermal stress calculation.

Step 3 - Thermal Stress Calculation

The current finite element model does not include any friction or gaps which, for example, would cause coupled effects of thermal and mechanical loads. Therefore, a standard de-coupled analysis is employed. The plate bending problem solved in Step 1 is restarted by first fixing the load point assuming that the load cell position remains unchanged after it was loaded to 2046 Newtons (460 lbs). This position is unaffected by the subsequent local laser heating. Then 
the temperature history of heating and cooling calculated in Step 2 is applied to the mechanical system. The final surface displacements are used to compare those measured at UAH by converting the optical fringes to displacements.

Since the laser heating spot is not at the center of the plate, only a one-half symmetry can be considered (see Figures $6 a$ and $6 b$ for the finite element mesh in the thermomechanical analysis when the laser annealing spot is located on the long axis of the plate). The same mesh is used in the thermal analysis (see Step 2 above) and the stress analyses (Step 1 and Step 3). The ABAQUS element type DC3D8 is used in thermal analysis and type C3D8 in stress analysis. All the elements are eight-noded bricks. The total number of elements is 9470 with 11,958 nodes. There are five layers of element through the thickness of the plate. An elastic-perfectly-plastic material response without strain hardening is assumed.

For Steps 1 and 3, the mechanical boundary conditions are identical to those for the quarter-plate model used in the pre-analysis discussed earlier (Section 3.2), except that the symmetric condition for the $\mathrm{Y}-\mathrm{Z}$ plane is no longer needed. The model is constrained in the $\mathrm{X}$-direction at point 0 which is the tip of the load cell (the nodal coordinates are $\mathrm{X}=\mathrm{Y}=\mathrm{Z}=0$ ). The thermal boundary conditions for Step 2 are the adiabatic condition on the $\mathrm{X}-\mathrm{Z}$ symmetric plane and free convection $\left(5.0 \mathrm{~W} / \mathrm{m}^{2} \cdot \mathrm{K},[10]\right)$ to the ambient temperature $(300 \mathrm{~K})$ on the model exterior surface.

Another finite element mesh was also developed and used for calculation in the case that the heated spot is located on the short axis of the plate. The detailed mesh near the heated spot and the load cell is identical to Figure $6 \mathrm{~b}$. Since the aspect ratio of the plate is 1.14 , no significant differences in the solutions are expected, especially the displacement field of interest is in the order of $1 \mu \mathrm{m}$.

\subsection{RESULTS}

Images of speckles are taken before and after the laser heating is applied. Subtracting these two images renders visible, bright-to-dark fringes. The relative displacement of the fringes is proportional to the wavelength of the laser beam. In the present case, a Helium Neon laser with wavelength $0.6328 \mu \mathrm{m}$ is used. The corresponding relative displacement between two fringes is $0.4475 \mu \mathrm{m}$.

The numerical procedure is performed in the same manner. The relative displacement field before and after heating is obtained by subtracting the displacements due to mechanical bending (Step 1 on page 4) from the displacements after cooling (Step 3 on page 5).

Most of the results presented in this report were obtained by prescribing a uniform temperature (i.e., the paint melting temperature, $485.15 \mathrm{~K}$ or $212^{\circ} \mathrm{C}$ ) over the heated spot. In all the heating cases investigated (heating times are in the neighborhood of six seconds), The temperature drops down to the room temperature $(300 \mathrm{~K})$ in about 5 to $8 \mathrm{~mm}$ away from the center of the heated spot. In other words, the majority of the test plate remains at the room temperature during laser heating.

Denoting the horizontal (X-direction) displacement by $U$ and the vertical displacement (Y-direction) by V, Figure 7 shows the U-contours after 2046 Newtons (460 lbs) were applied to the center of the plate. The displacements in micro-meters are labeled on the contour lines in the figure. Note that the line for $U=0$ should occur exactly along $X=0$ by symmetry. However, this is a half plate model (symmetric with respect to $\mathrm{Y}=0$ ) and zero horizontal displacements need not be enforced along $X=0$ except at the tip of the load cell $(\mathrm{X}=\mathrm{Y}=\mathrm{Z}=0)$. Therefore, due to a slight numerical imbalance, the $\mathrm{U}=0$ line was shifted about $0.4 \mathrm{~mm}$ from the centerline on the heated side of the plate. This will not impact the final result because the same mesh and boundary conditions were used to calculate the thermal stress after heating and cooling (Figure 8 for U-displacements), and only additional 
displacements due to laser annealing is relevant. By subtracting displacement field in Figure 7 from that in Figure 8, the horizontal displacements due to laser annealing alone are shown in Figure 9. Similarly, the vertical displacements (V) around the heated spot due to laser annealing alone could be obtained and are shown in Figure 10. Note that the out-ofplane displacements in Z-direction are not considered in developing the laser annealing and speckle interferometry technique for the current application in which the surfaces are essentially flat and have very small curvatures after the mechanical loading.

To compare the calculated displacements with the experimental results, additional treatment is needed for the U-displacement. Since the speckle fringes can only indicate relative displacements, the absolute displacement may not always be available, unless a fringe corresponding to a known displacement is identified, such as on a fixed boundary. In the present case, the horizontal displacements near the heated spot are nowhere zero. Therefore, the absolute displacements in the X-direction (U) are indeterminate within the image frame taken at UAH. Only relative displacements are available from one fringe to another. This "unit" relative displacement is thus $0.4475 \mu \mathrm{m}$. Taking arbitrarily the horizontal displacement at the center of the heated spot as the reference point, the displacement contours for $U$ are re-plotted after subtracting the value at the center of the heated spot. The adjusted contour plot is then overlaid on the speckle image taken at the UAH as shown in Figure 11. It can be seen that there is a dark fringe around the heated spot (bright area). This corresponds to a one-half fringes (relative displacement $=0.4475$ $\mu \mathrm{m} \div 2$ ). The corresponding contour lines constructed from the finite element result show that the relative displacement is about $0.3 \mu \mathrm{m}$. The order of magnitude of the displacements is in agreement.

The contour plot is straight forward for the vertical displacements (V) because it is known that $\mathrm{V}$ is zero on the long axis due to symmetry. Therefore, Figure 10 can be overlaid directly on top of the fringe pattern obtained at UAH. Figure 12 allows direct comparison of the calculated and experimental results. A zeroth order fringe, although it is somewhat gray in the UAH image, should exist along the $\mathrm{X}$-axis. The darker area above the $\mathrm{X}$-axis corresponds to the next dark fringe. The relative displacement in the $\mathrm{Y}$-direction (V) between these two fringes is therefore about $0.4475 \mu \mathrm{m}$. In this case, it is also the absolute V-displacement for the darker region in the UAH image. The contour lines show that the calculated V-displacement there is about 0.4 to $0.5 \mu \mathrm{m}$. The numerical and experimental results are consistent in the order of magnitude.

Note that the fringes obtained at UAH should be symmetric with respect to the long axis of the plate (see the overlaid X-axis in Figures 11 and 12). However, the spurious noise and vibration in the UAH laboratory might cause the flickering of images. Therefore, the fringes in Figures 11 and 12 do not appear to be exactly symmetric at the moment when the image frame was captured by a camera. Note that these speckle fringes in Figures 11 and 12 have been digitally inverted from those in Reference 4 for direct comparison with the calculated results.

The finite element results discussed so far are based on the condition that uniform temperature is prescribed over the heated spot. As mentioned earlier on page 5 in Step 2 of Section 3.3, equivalent solution may also be obtained by providing heat flux to the heated spot until a proper temperature profile is reached on that spot. In this case the heating time and heat flux are determined by a preliminary thermal analysis with extra heating time for a given heat flux input. It was found that the temperature at the heated spot would be everywhere above the melting temperature of the temperature sensitive paint $(485.15 \mathrm{~K}$ or $212^{\circ} \mathrm{C}$ ), if the heat flux is raised linearly to $494.4 \mathrm{~W} / \mathrm{cm}^{2}$ in 6.18 seconds (note that the heat flux rate is $80 \mathrm{~W} / \mathrm{cm}^{2} \cdot \mathrm{sec}$ as discussed earlier). The resulting relative horizontal displacement contours with a reference set to the U-displacement at the heated spot are plotted in Figure 13. The V-displacement contours are shown in Figure 14. It can be seen that the displacements are similar to those shown in Figures 11 and 12 which were obtained with a uniform temperature of $485.15 \mathrm{~K}$ over the heated spot. Note that the total heat input 
to the test plate is higher in the case for Figures 13 and 14 which are the results of prescribing heat flux.

\subsection{CONCLUSION AND DISCUSSION}

The calculated and measured displacements are in good agreement near the laser heating spot in a biaxial bending stress field. It appears that the displacement due to heating induced plastic deformation (as a result of lowered yield stress as temperature rises) is less sensitive to the heat input to the material. Rather, the temperature achievable at the heated spot has a more direct impact to the displacement because the permanent deformation is a result of thermal expansion and yield stress which are temperature dependent. Therefore, the key issue for the laser annealing technique appears to be the capability to maintain an elevated temperature in a small area so that a measurable plastic deformation can be captured by a laser speckle interferometer. This capability depends on the thermal and mechanical properties of the material, and the power of the laser beam. In general, for a given power of a laser beam, it is easier to achieve the expected result for a material with low thermal diffusivity $(\mathrm{k} / \rho \mathrm{c}$, where $\mathrm{k}$ is the thermal conductivity, $\rho$ is the density, and $\mathrm{c}$ is the specific heat) and a rapidly decreasing yield stress as the temperature rises.

In the laboratory testing, higher fringe resolution may be required to be effectively compared with the finite element solutions. To significantly increase the magnitude of measurable displacements, an experimental design change might be desirable. On the other hand, a refined finite element analysis may be needed for better modeling the application of the mechanical and thermal loads. The melting of the temperature sensitive paint involves phase change simulation and is complicated. This may be pursued if a high degree of solution accuracy is of interest. From a practical point of view, it would be useful if more experimental data are available for benchmarking or calibrating the performance of the finite element analysis (such as the overall temperature distribution on both sides of the plate, and full field interferometry fringe patterns, etc.).

\subsection{REFERENCES}

[1] Pechersky, M. J., Method for Measuring Residual Stresses in Materials by Plastically Deforming the Material and Interference Pattern Comparison, United States Patent No. $5,432,595$, July 11,1995 .

[2] Pechersky, M. J., Miller, R. F. and Vikram, C. S., "Residual Stress Measurements with Laser Correlation Interferometry and Local Heat Treating," Optical Engineering, Vol. 34, No. 10, pp. 2964- 2971, 1995.

[3] Vikram, C. S., Pechersky, M. J., Feng C. and Engelhaupt, D. "Residual-Stress Analysis by Local Laser Heating and Speckle Correlation Interferometry," Experimental Techniques, Vol. 20, No. 6, pp. 27 - 30, 1996.

[4] Vikram, C. S., "Development of Residual Stress Measurement Techniques with Laser Annealing and Speckle Interferometry - Phase II (Thirteen Bimonthly Technical Report)," DOE Principal Contract DE-AC09-89SR18035, Subcontract No. AB62848-0, Center for Applied Optics, University of Alabama, Huntsville, Alabama, December 1996.

[5] ABAQUS/STANDARD, Version 5.5, Hibbitt, Karlsson and Sorensen, Inc., Pawtucket, Rhode Island, 1997.

[6] MSC/PATRAN, MacNeal-Schwendler Corporation, Los Angeles, California, 1996. 
[7] Miller, R. F., "Results of the Analytical Support Effort for the CAO Subcontract (U)," SRL-MTS-93-1071, Interoffice Memorandum, Westinghouse Savannah River Company, Aiken, SC, July 23, 1993.

[8] Peckner, D and Bernstein, I. M., Handbook of Stainless Steels, MeGraw-Hill Book Company, New York, 1977.

[9] Certificate of Tests, Washington Specialty Metals, Buffalo Grove, Illinois, July 15, 1996.

[10] Davis, J. R., ASM Specialty Handbook, Stainless Steels, ASM International, Materials Park, Ohio, 1994.

[11] Incropera, F. P. and Dewitt, D. P., Fundamentals of Heat and Mass Transfer, second edition, John Wiley \& Sons, Inc., New York, 1985.

[12] Özisik, M. N., Heat Transfer, A Basic Approach, McGraw-Hill Book Company, New York, 1985.

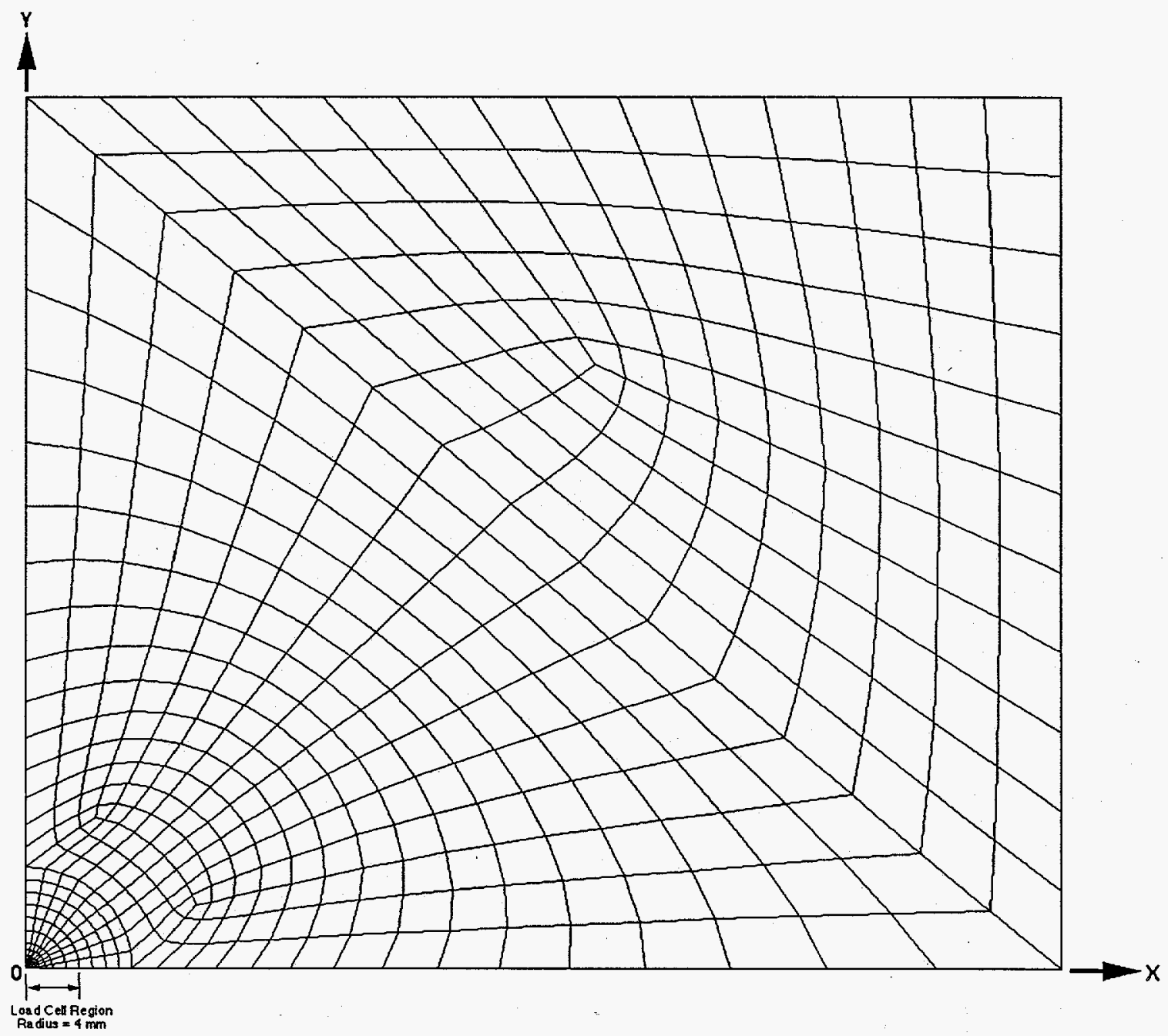

FIGURE 1 - Finite Element Mesh for the Quarter Plate Model (Pre-Analysis Mechanical Model). 


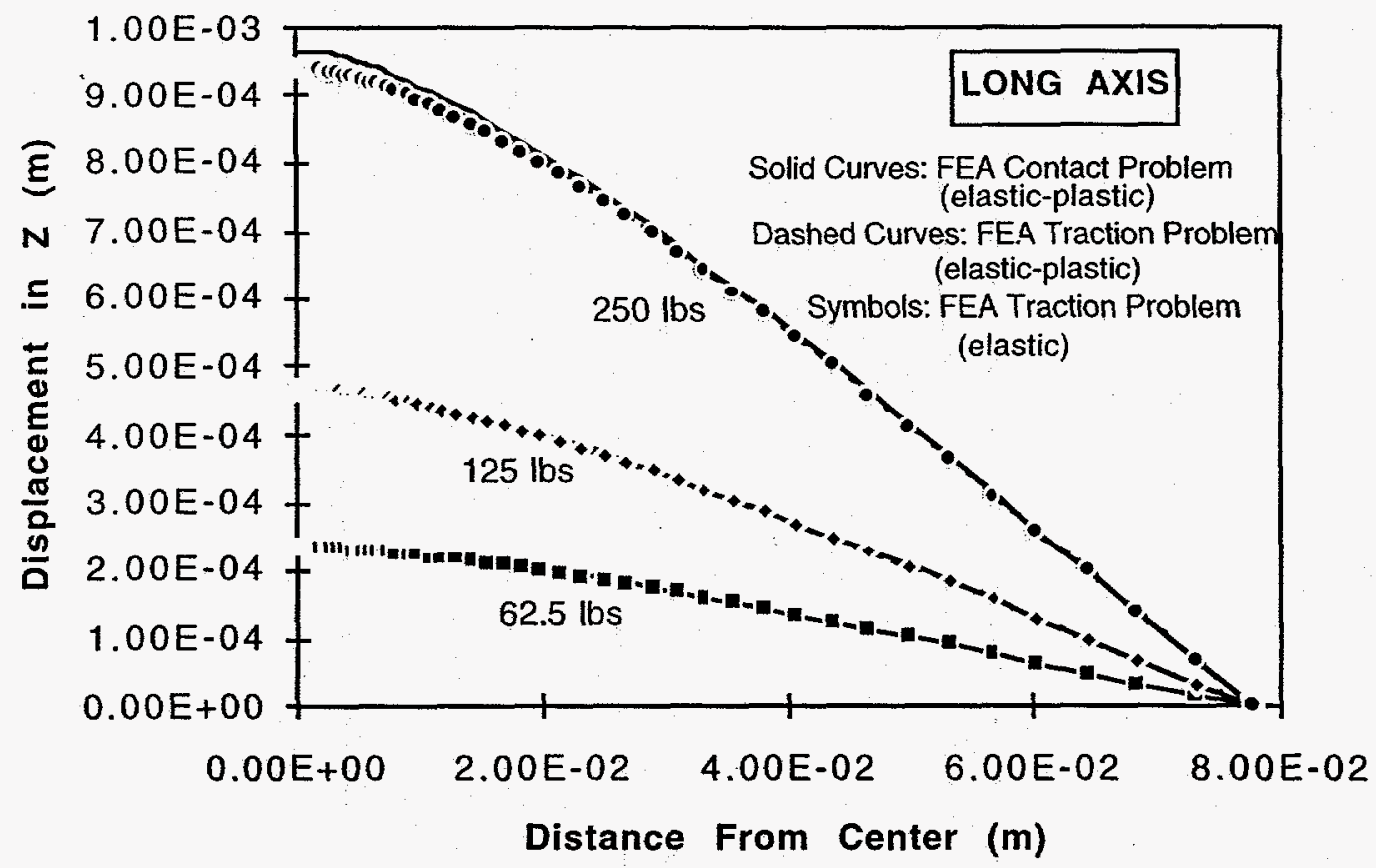

FIGURE 2 - Out-of-Plane Displacements from Plate Center to the Edge along the Long Axis (Comparison of Various Numerical Approaches).

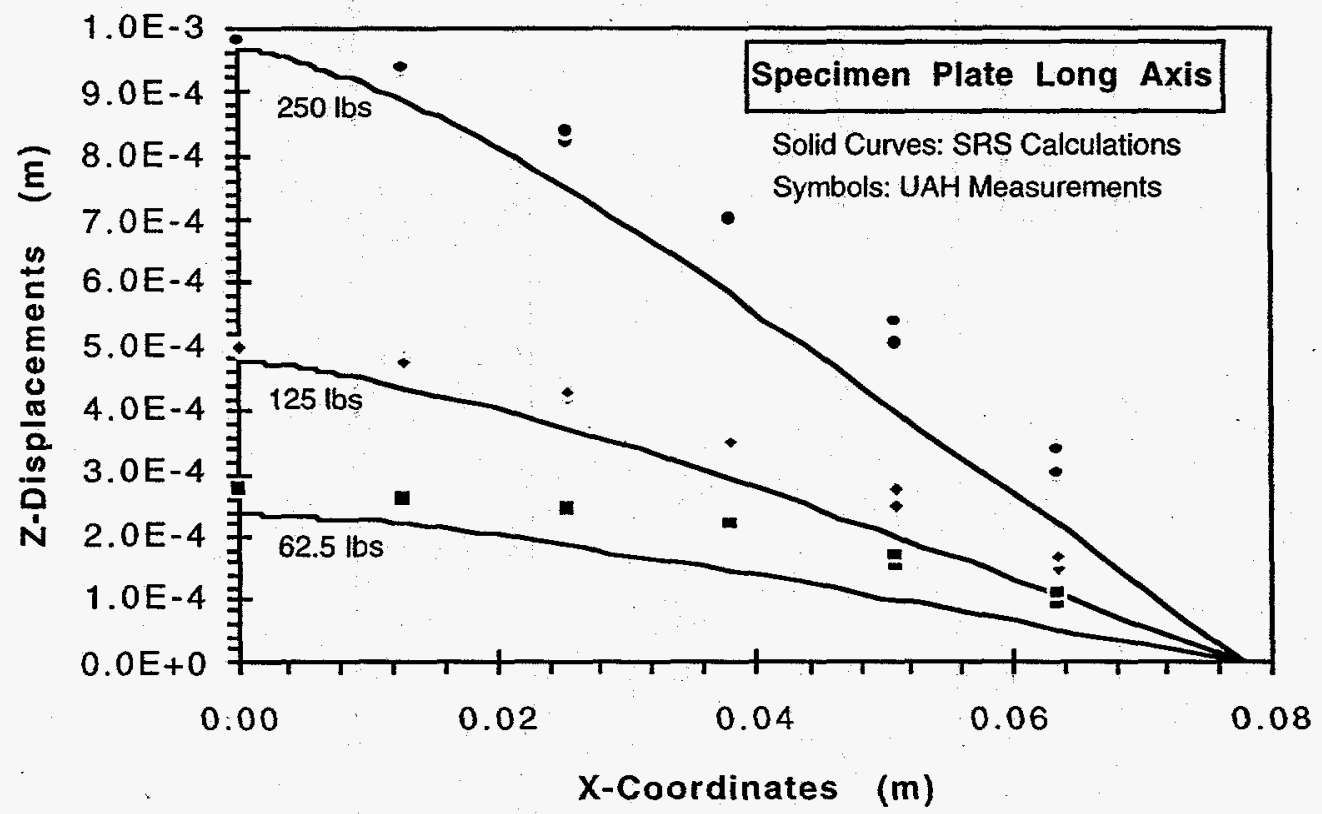

FIGURE 3 - Out-of-Plane Displacements from Plate Center to the Edge along the Long Axis (Comparison of Experimental Data). 


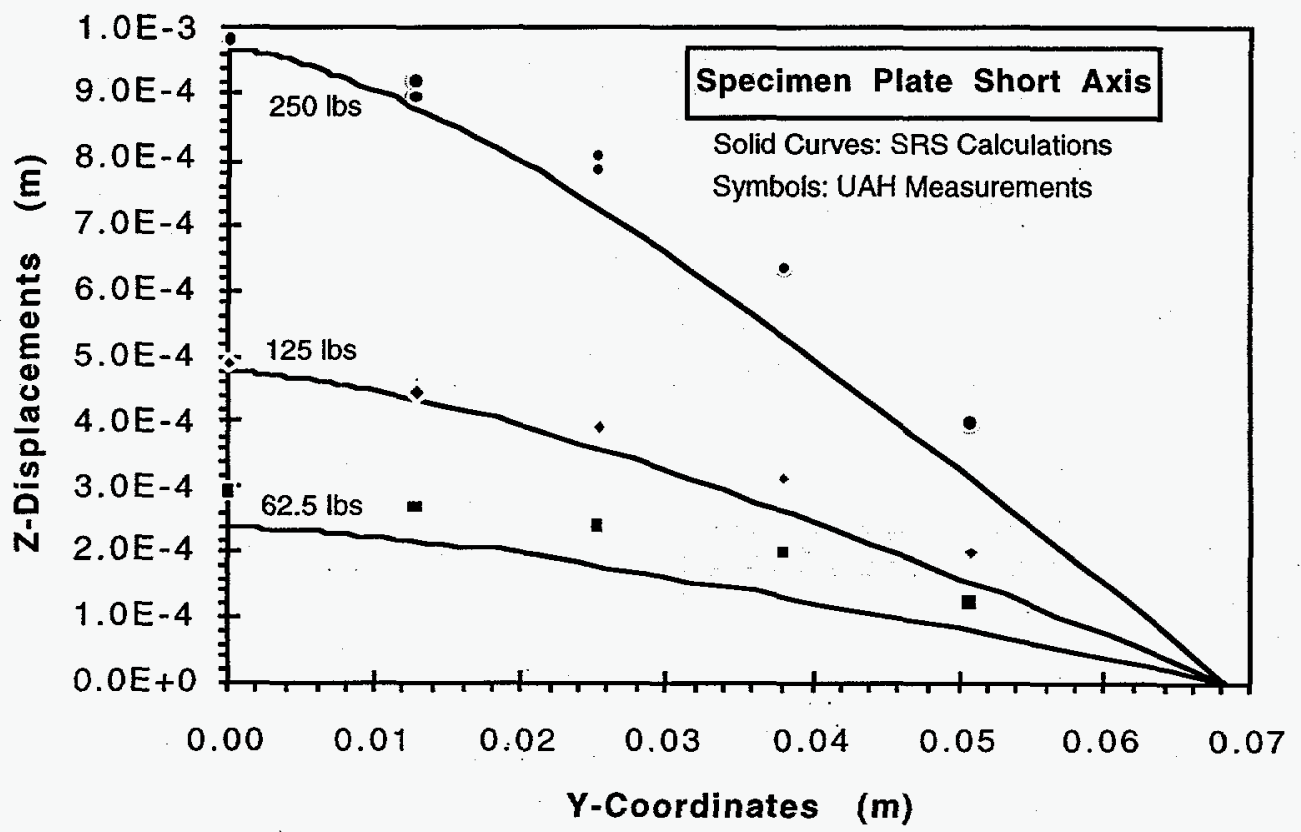

FIGURE 4 - Out-of-Plane Displacements from Plate Center to the Edge along the Short Axis (Comparison of Experimental Data).

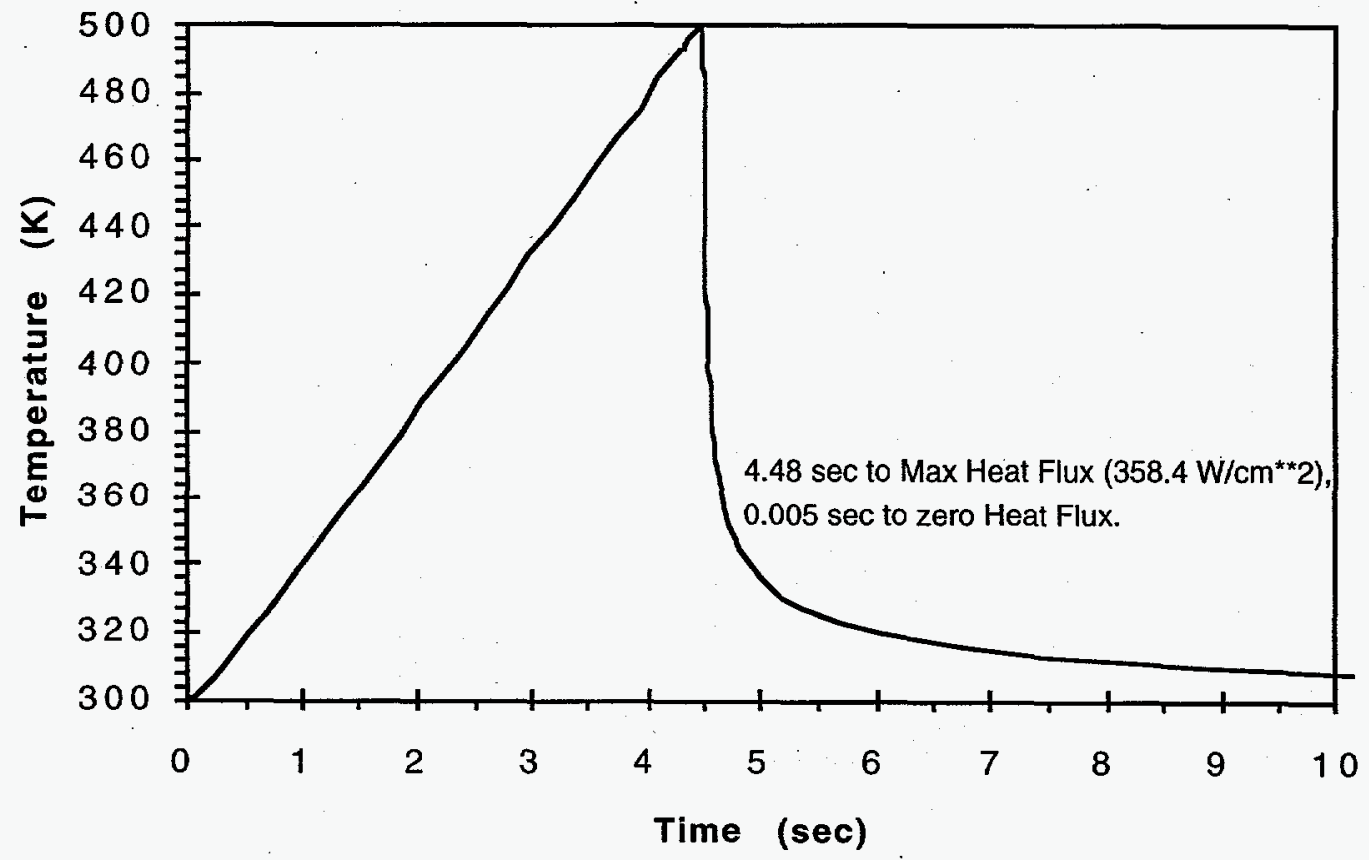

FIGURE 5 - Typical Temperature Response by Imposing Linear Heat Flux with respect to Time. 


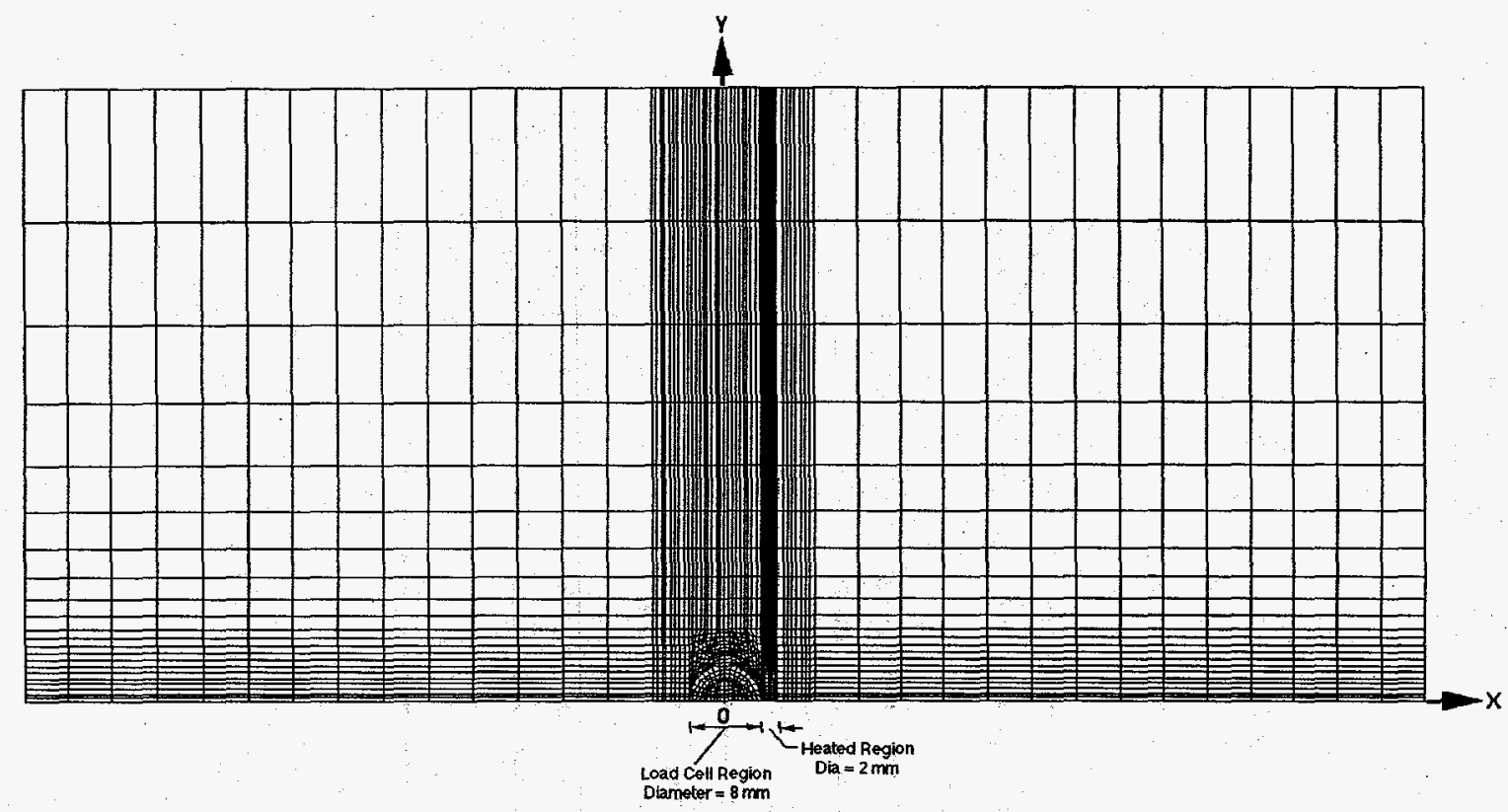

FIGURE 6a - Overall Finite Element Mesh for the Half Plate Thermomechanical Model.

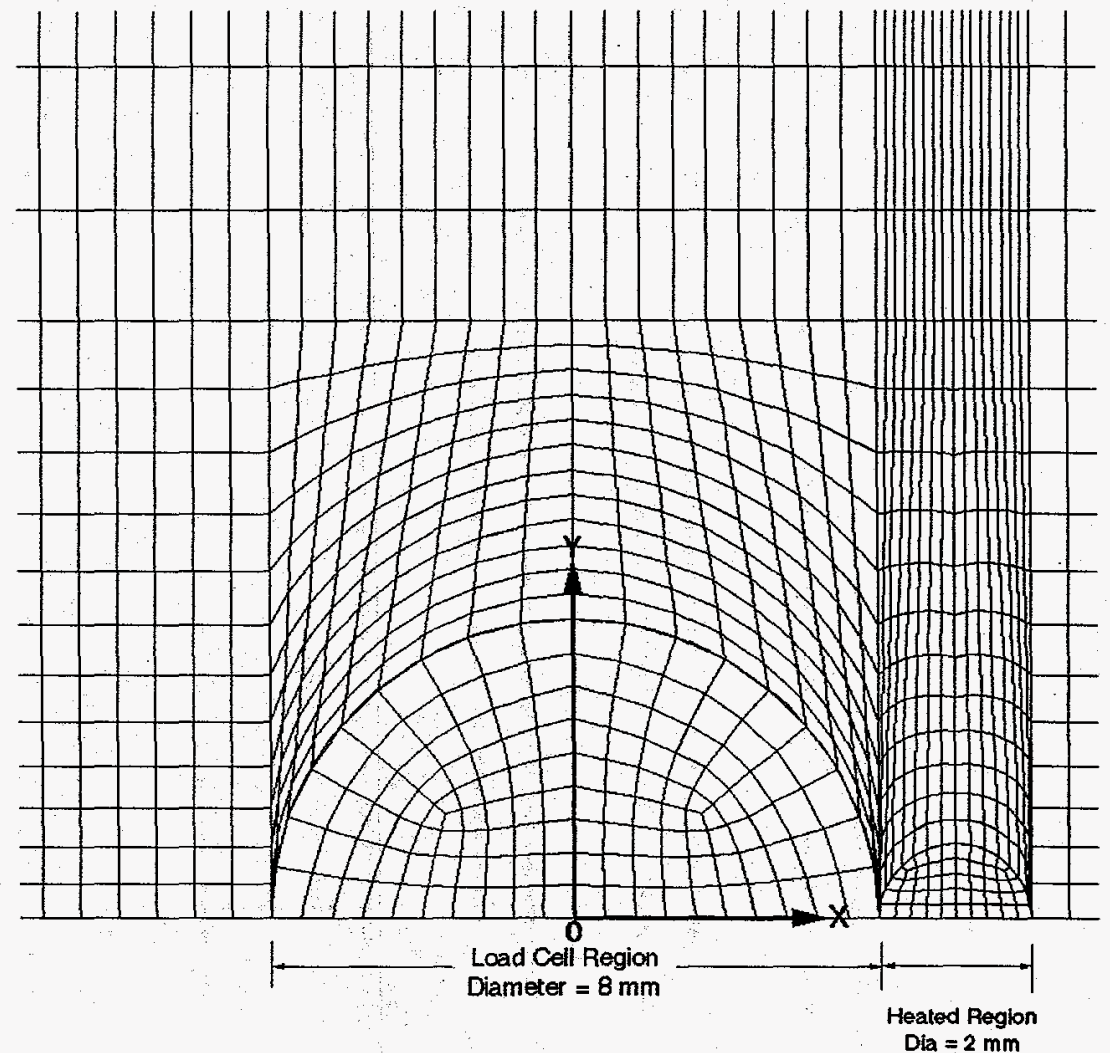

FIGURE 6b - Detailed Finite Element Mesh for the Load Cell and Heated Areas of the Half Plate Thermomechanical Model. 


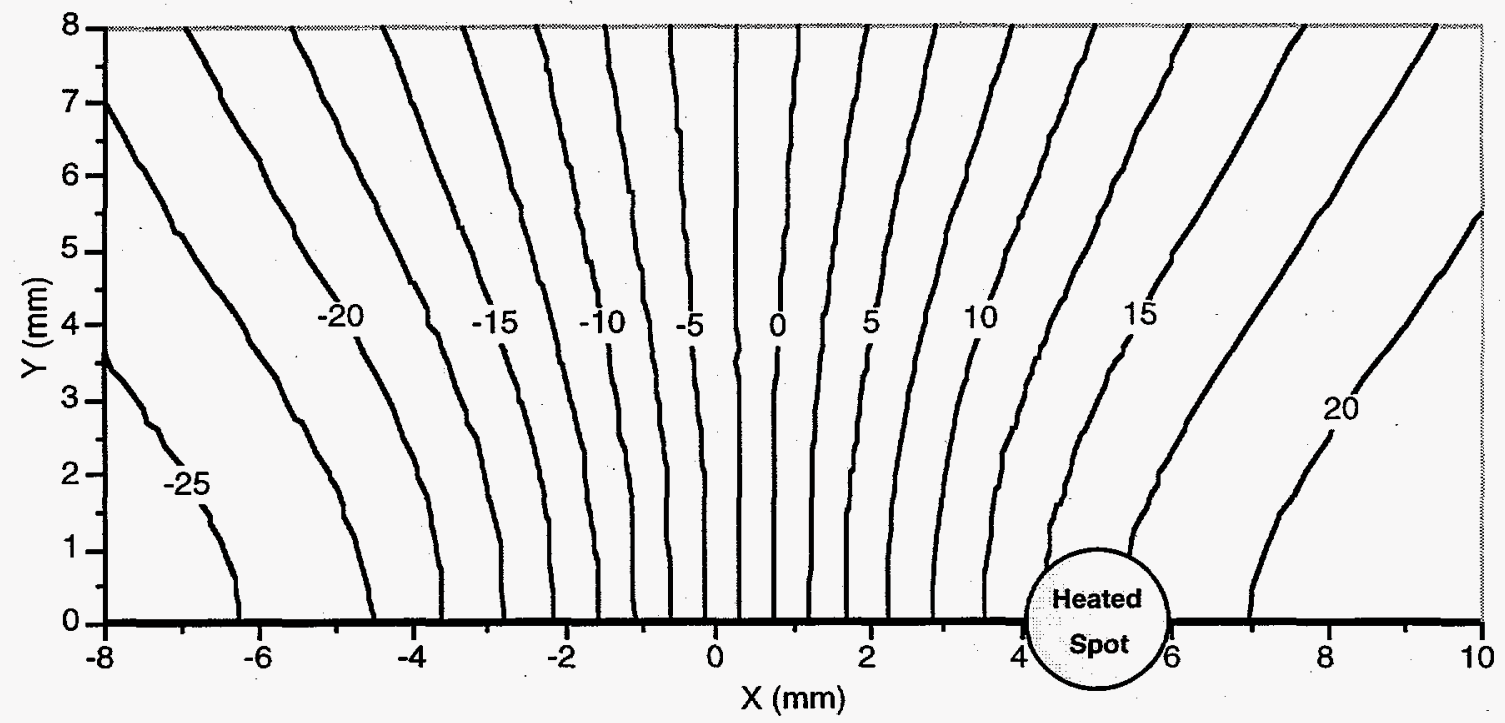

FIGURE 7 - In-Plane Horizontal Displacement Contours after 2046 Newtons (460 lbs) Load Applied to the Plate Center (The values on the contour lines are the displacements in $\mu \mathrm{m}$ ).

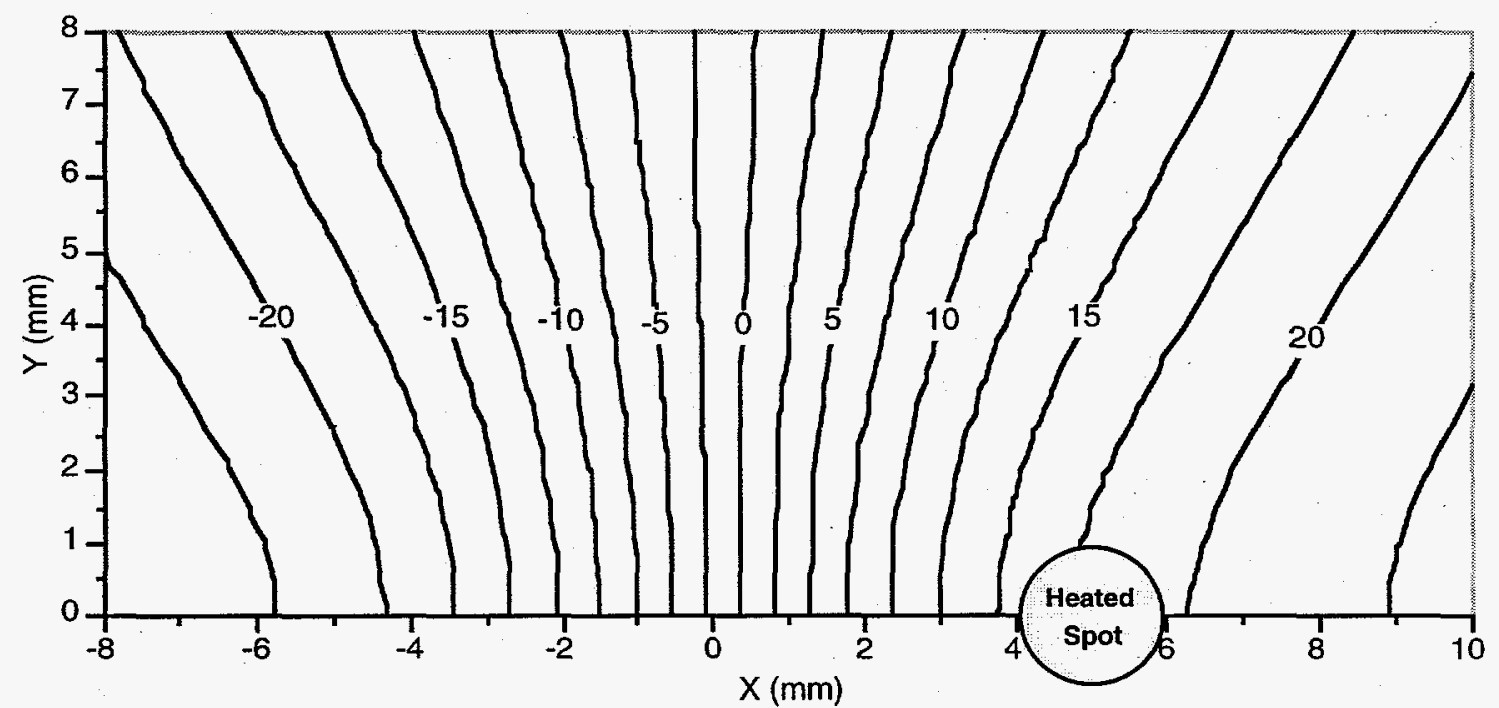

FIGURE 8 - In-Plane Horizontal Displacement Contours after the Heated Spot Uniformly Reaches $485 \mathrm{~K}\left(212^{\circ} \mathrm{C}\right)$. Heated Spot is on the Long Axis (The values on the contour lines are the displacements in $\mu \mathrm{m}$ ). 


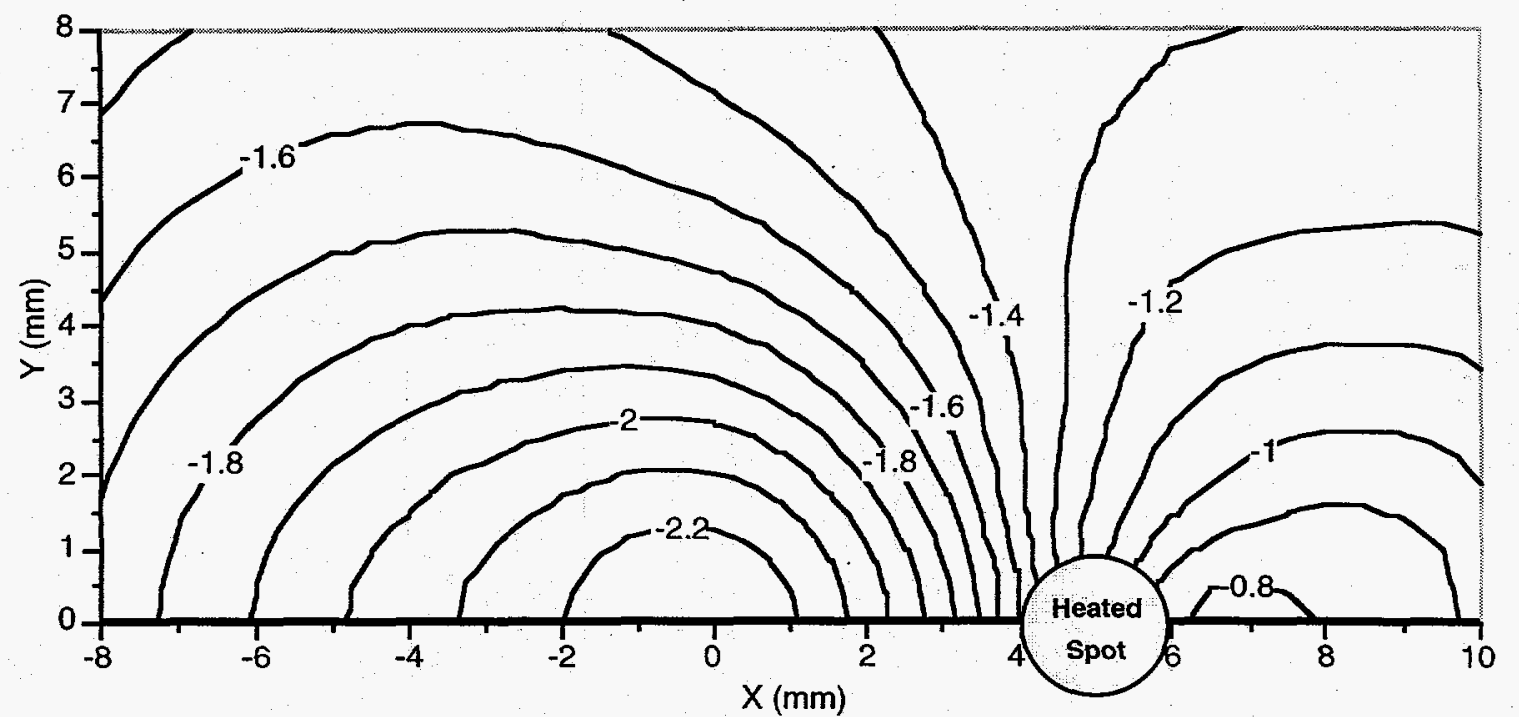

FIGURE 9 - Additional Horizontal Displacement due to Laser Annealing (Figure 8 subtracts Figure 7). Heated Spot is on the Long Axis (The values on the contour lines are the displacements in $\mu \mathrm{m}$ ).

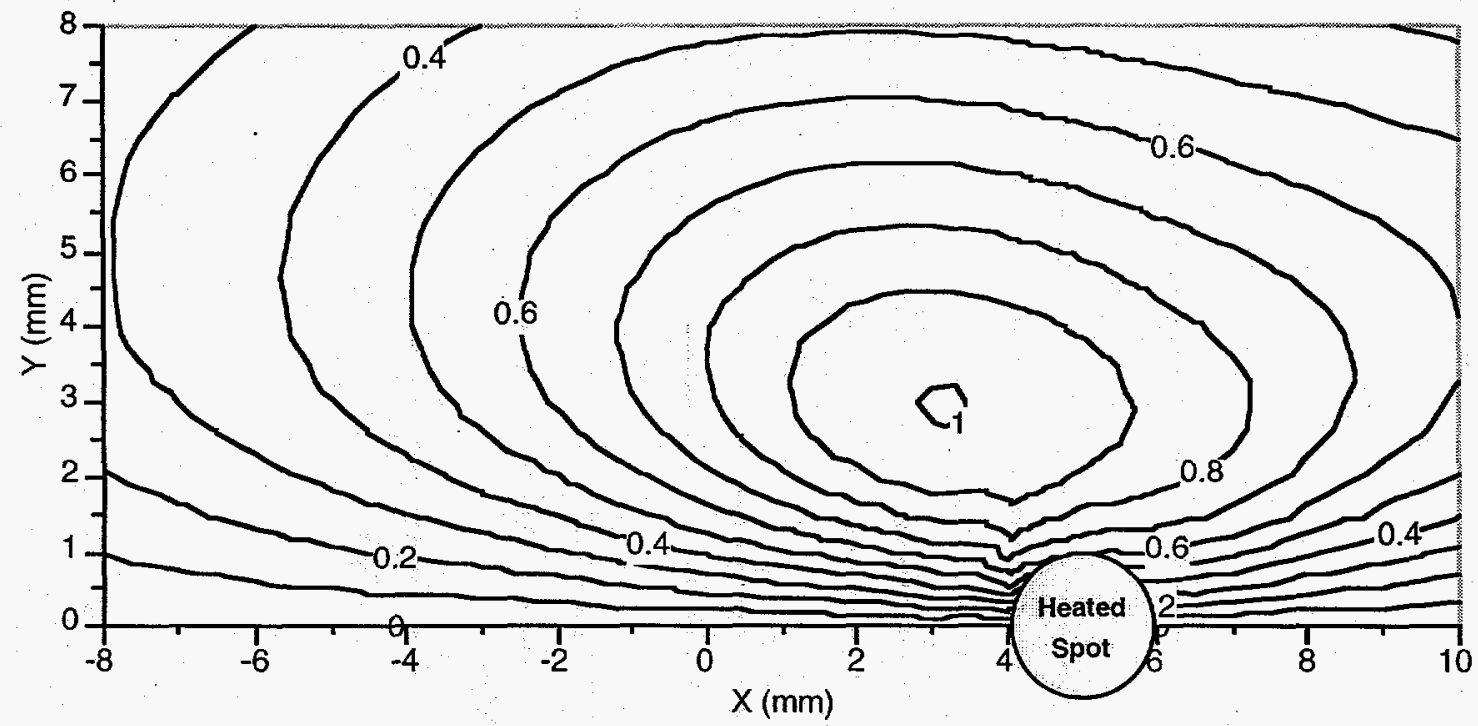

FIGURE 10 - Additional Vertical Displacement due to Laser Annealing. Heated Spot is on the Long Axis (The values on the contour lines are the displacements in $\mu \mathrm{m}$ ). 


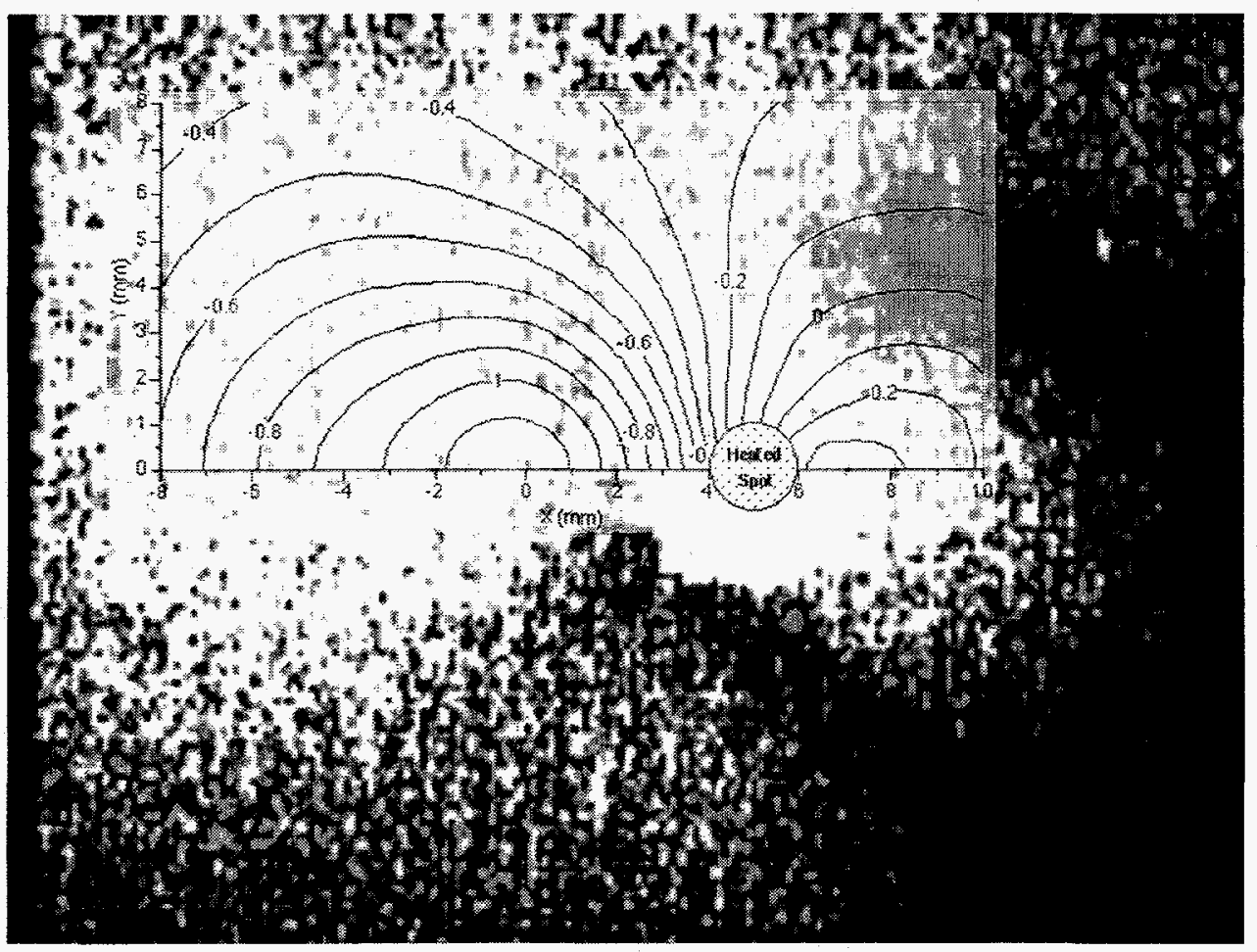

FIGURE 11 - Relative Displacements in Horizontal Direction with respect to the Displacement at the Heated Spot. Speckle Fringes were Obtained at the University of Alabama. Plate Center is on the Left of Heated Spot.

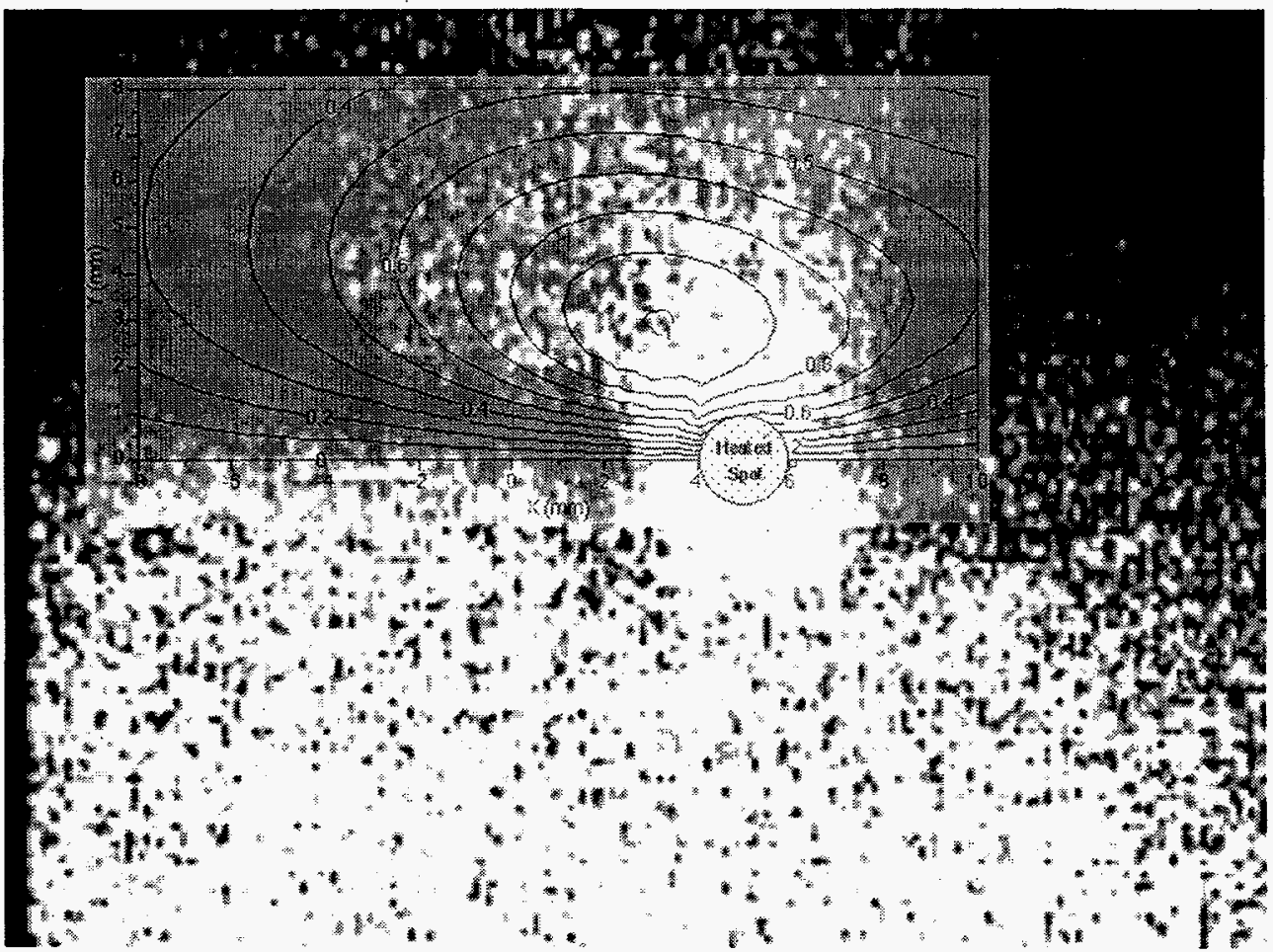

FIGURE 12 - Relative Displacements in Vertical Direction. Speckle Fringes were Obtained at the University of Alabama. Plate Center is on the Left of Heated Spot. 


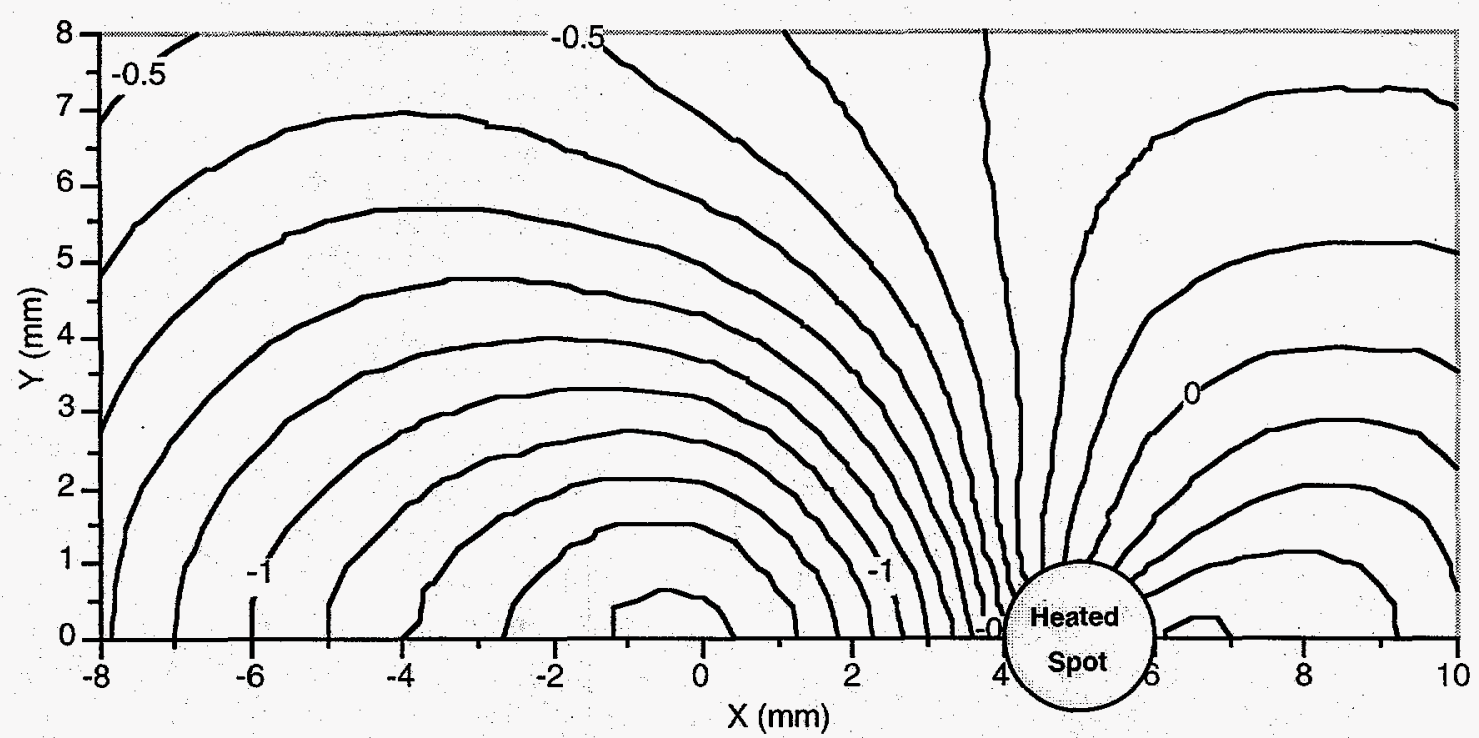

FIGURE 13 - In-Plane Relative Displacements in Horizontal Direction with respect to the Displacement at the Heated Spot. Heat Flux is $494 \mathrm{~W} / \mathrm{cm}^{2}$ and Temperatures $\geq 485 \mathrm{~K}\left(212^{\circ} \mathrm{C}\right)$ at the Heated Spot on the Long Axis. The Values on the Contour Lines are the Displacements in $\mu \mathrm{m}$.

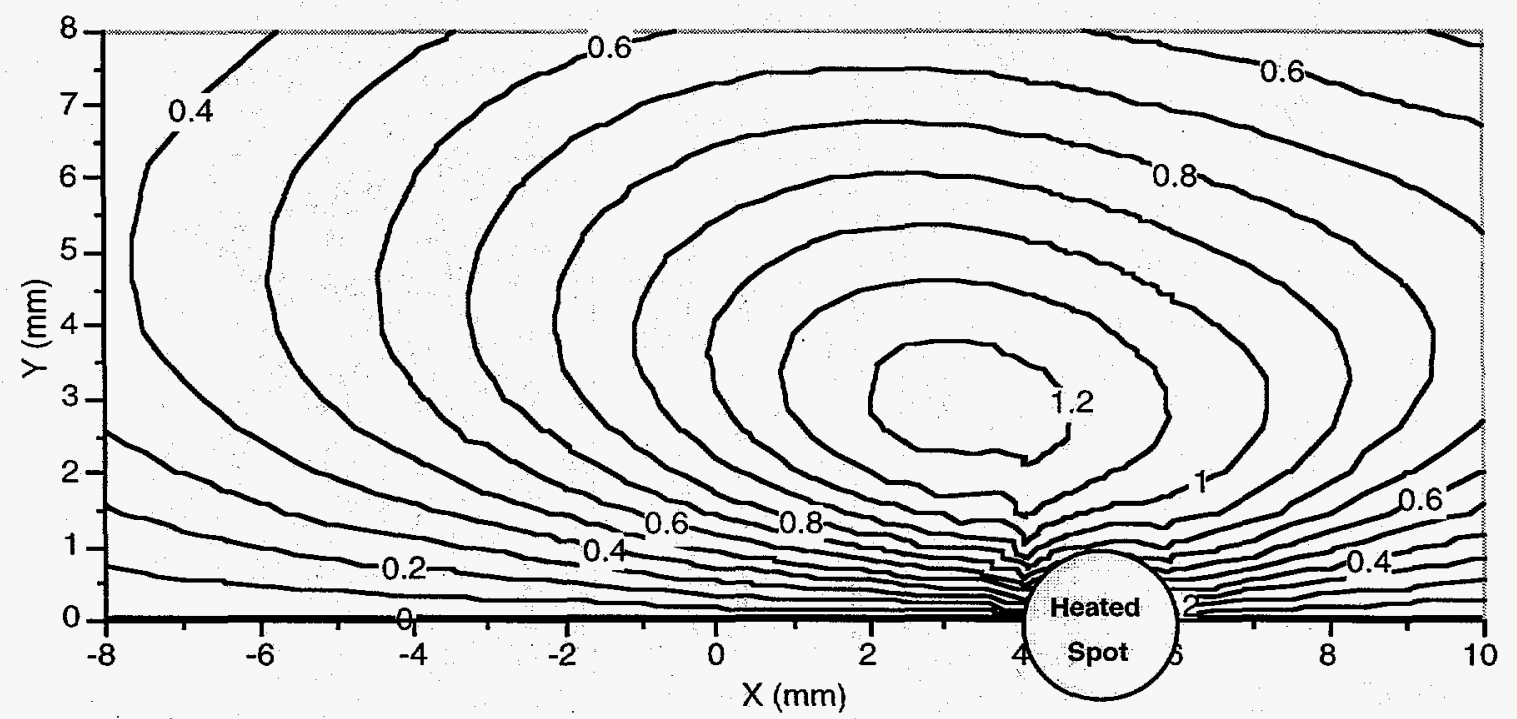

FIGURE 14 - In-Plane Relative Displacements in Vertical Direction. Heat Flux is $494 \mathrm{~W} / \mathrm{cm}^{2}$ and Temperatures $\geq 485 \mathrm{~K}\left(212^{\circ} \mathrm{C}\right)$ at the Heated Spot on the Long Axis. The Values on the Contour Lines are the Displacements in $\mu \mathrm{m}$. 


\section{WESTINGHOUSE SAVANNAH RIVER COMPANY \\ REPORT WSRC-TR-97-00294}

\section{DISTRIBUTION}

\section{SAVANNAH RIVER SITE}

C. R. Wolfe, 773-A

T. L. Capeletti, 773-41A

N. C. Iyer, 773-A

M. J. Pechersky, 773-A

R. L. Sindelar, 773-41A

P. S. Lam, 773-41A

D. T. Rankin, 773-A

M. J. Morgan, 773-A

N. K. Gupta, 773-42A 